\title{
Quality Assurance of the Pulmonary Function Technologist
}

\author{
Jeffrey M Haynes RRT RPFT
}

\author{
Introduction \\ Technologist Selection \\ Making an Informed Choice \\ Applicant Motivation \\ Qualifications \\ Beyond the Résumé and the Interview \\ Technologist Training and Maintenance \\ Training \\ Test Acceptability and Reproducibility Feedback \\ Technologist Performance Feedbacks \\ Laboratory Accreditation \\ Summary
}

\begin{abstract}
The skill and work habits of the pulmonary function technologist are central to the quality of patient testing. Pulmonary function technologists should be chosen carefully. The pulmonary function technologists must be intelligent, conscientious, and possess critical thinking skills. Studies are needed to better identify which kinds of personality traits correlate with superior job performance and whether or not such traits can be reliably identified by standardized testing. Monitoring of technologist performance and technologist feedback improves the quality of testing but is utilized by only a minority of clinical laboratories. Pulmonary function laboratory accreditation is urgently needed to protect the public from potential misdiagnosis and inappropriate treatment due to spurious data. Key words: pulmonary function tests; healthcare quality assurance; guideline adherence; clinical competence. [Respir Care 2012;57(1):114-122. (C) 2012 Daedalus Enterprises]
\end{abstract}

\section{Introduction}

Pulmonary function tests (PFTs) translate respiratory functionality into usable numbers. ${ }^{1-3}$ What we learn from PFT data can have an enormous impact on our understanding of the health of a population, ${ }^{4,5}$ the natural history and treatment of specific diseases, ${ }^{6-8}$ and the best care for the

Jeffrey M Haynes RRT RPFT is affiliated with the Department of Respiratory Therapy, St Joseph Hospital, Nashua, New Hampshire.

Mr Haynes presented a version of this paper at the 48th RESPIRATORY CARE Journal Conference, "Pulmonary Function Testing," held March 2527, 2011, in Tampa, Florida.

The author has disclosed no conflicts of interest. patient sitting a few feet away from us. ${ }^{9}$ However, the strength of our conclusions and the legitimacy of our interventions are only as powerful as the validity of the reported data.

There are 3 core elements that are essential to capturing valid pulmonary function data: accurate and precise instrumentation; cooperative testing subject capable of performing breathing maneuvers within the tolerances of the test architecture; pulmonary function technologist with the

Correspondence: Jeffrey M. Haynes RRT RPFT, Department of Respiratory Therapy, St Joseph Hospital, 172 Kinsley Street, Nashua NH 03060. E-mail: jhaynes@sjhnh.org.

DOI: $10.4187 /$ respcare. 01401 
ability and the desire to manage the laboratory and properly to orchestrate testing. Of these 3 core elements, the pulmonary function technologist has clearly attracted the least attention and has been subjected to the least scrutiny. However, without a highly skilled and motivated technologist, the above mentioned collaboration is doomed to unravel and fail. Perhaps Wanger put it best: "the first and foremost issue in the pulmonary function laboratory quality-assurance program is the technologist."10 This paper will focus on how to obtain acceptable and reproducible effort from the pulmonary function technologist.

\section{Technologist Selection}

\section{Making an Informed Choice}

When preparing to purchase a new pulmonary function system, most managers would evaluate more than one product on the market. The pros and cons of different products are weighed to try to make the best choice for the laboratory. Carefully choosing the best pulmonary function system for one's laboratory is very important, since making the wrong choice may carry the burden of years of dissatisfaction and remorse. The easiest headache to treat is the one you never get. However, since pulmonary function systems are manufactured to American Thoracic Society/ European Respiratory Society (ATS/ERS) specifications, ${ }^{11-13}$ differences in product design should generally affect only ease of use, maintenance, and reliability, and not usually have a major impact on test results. ${ }^{14-17}$ Of course this can never be assumed. ${ }^{17,18}$ However, how often is such vigilance and thoughtfulness placed on the selection of a pulmonary function technologist? A high level of scrutiny must be given to the applicant wishing to practice in the PFT laboratory, since only a quality technologist can be relied upon to produce quality data. ${ }^{19}$

\section{Applicant Motivation}

In the United States, particularly in community hospitals, many pulmonary function technologists are respiratory therapists (RT). Recruiting RTs to work in the PFT laboratory is logical, since many laboratories are part of the RT department, and pulmonary function testing is a part of an RT's training. However, some RTs may wish to enter the PFT laboratory for the wrong reasons. Ideally, RTs seeking to enter the PFT laboratory would be motivated by a desire to acquire a more in-depth understanding of respiratory physiology and to experience the satisfaction that comes from working in a scientific laboratory environment. However, many times RTs express interest in working in the PFT laboratory because of a desire to escape from some other situation, such as the hectic intensive care unit or the often heavy work loads of floor therapy. It is also true that some RTs may view working in the PFT laboratory as less labor intensive and might view an opening in the PFT laboratory as an avenue to work less; however, working in the PFT lab is not a less demanding job than working in the intensive care unit: it is rather a different kind of work. Therefore, while asking an applicant "Why do you want to work in the PFT lab?" may appear on its face to be an inconsequential interview icebreaker, I submit that this is a very important question from which valuable information regarding an applicant's motivations can be learned. Individuals who are motivated to enter the PFT laboratory simply to remove themselves from another situation or to lighten their work load are not good candidates for hire.

When any clinician first enters the PFT laboratory, they are a student. Initial student enthusiasm and motivation to learn can be misleading, since these may dissipate rather quickly. This is a common observation in everyday life and is also documented by some data in healthcare students. Hastings et $\mathrm{al}^{20}$ documented a shift away from mastery motivation (desire to master learning material) toward performance motivation (learn enough to pass the test) and academic alienation (no desire to learn) over time in pharmacy students in a university setting. Students who are motivated by the desire to become an exceptional member of their profession (social utility) may be expected to perform better over time than those who embrace the concept of mastery motivation merely to gain their instructor's or supervisor's approval (social desirability). ${ }^{21}$

\section{Qualifications}

Recommendations regarding technologist qualifications have evolved over several decades; however, what has not changed is that these recommendations are based almost completely on expert opinion rather than data. In 1955 Franklin et $\mathrm{al}^{1}$ described the clinical utility of forced spirometry or "expirograms." At that time pulmonary function testing was in its infancy, but even then the authors recognized that a pulmonary function laboratory required "highly trained personnel." In 1968 Woolf described the organization of the pulmonary function laboratory at Toronto General Hospital. ${ }^{22}$ In regards to technologists' qualifications he simply states that "it is essential that the technicians for the laboratory should be well trained and reliable individuals who can work with the minimum of supervision." In 1972 Hughes and Empey ${ }^{23}$ described their experience managing a pulmonary function laboratory in the Department of Chest Diseases at London Hospital over a 10-year period. Hughes and Empey are perhaps the first to recommend that technologists receive formal classroom training in physiologic measurements. They also made the observation that technologists with a greater educational background are required to deal with the complexities of 
instrumentation and research. Ten years later the ATS issued a position paper specifically addressing pulmonary function technologist qualifications. ${ }^{24}$ At that time the recommended minimal educational background was a high school diploma and 6-12 months of training in the pulmonary function laboratory. The issuing committee suggested that training in pulmonary function technology and/or respiratory therapy could be expected to shorten training time; however, this type of formal training and credential acquisition were highly recommended only for supervisory staff and for an individual serving as a chief pulmonary function technologist. The most recent recommendations regarding technologist qualifications were issued by the "ATS/ERS Task Force for Standardization of Lung Function Testing" in 1995.25 This guideline recommends a minimum of 2 years of college education, with an emphasis on health-related sciences generally, and more specifically recommends that technologists, "need to be familiar with the theory and practical aspects of all commonly applied techniques, measurements, calibrations, hygiene, quality control and other aspects of testing, as well as having a basic background knowledge in lung physiology and pathology."

In terms of the importance of credentialing, Enright et al showed in an uncontrolled study of 18,000 consecutive spirometry tests that experienced credentialed technologists working in a pulmonary function laboratory were able to facilitate ATS compliant tests $90 \%$ of the time. ${ }^{19}$ However, a respiratory therapy credential alone does not predict good testing performance. From tests that were performed by credentialed RTs, Stoller et al ${ }^{26}$ documented a bedside spirometry acceptability rate of only $15 \%$. Even after considerable training and ongoing therapist feedback, this value rose only to $63 \%$. Data are clearly lacking in regards to technologist performance and the acquisition of the National Board for Respiratory Care's Certified Pulmonary Function Technologist (CPFT) and Registered Pulmonary Function Technologist (RPFT) credentials. However, all technologists should be encouraged to take the CPFT and RPFT exams. Studying for the CPFT and RPFT exams is an excellent educational opportunity, and passing the exam demonstrates job-specific aptitude and a minimum level of competency for both entry level (CPFT) and advanced practitioners (RPFT).

\section{Beyond the Résumé and the Interview}

Many businesses across the economic spectrum rely less on résumé content and the traditional interviewing process and have shifted their attention toward pre-employment testing of aptitude and personality traits for making hiring decisions. The review of a résumé and interviews are used to help an employer make his or her best guess on whether or not an applicant will be able to perform job tasks sat- isfactorily and will maintain job performance over an extended period of time. However, these best guesses are non-scientific, subject to the employer's bias and insightfulness, and are, of course, often wrong. In 2001 Stoller and colleagues reported an annual RT turnover rate ranging between 3-18\% among the 9 hospitals in the Cleveland Clinic health system. ${ }^{27}$ At that time the cost of training each RT approached $\$ 3,500$. In the case of a pulmonary function technologist, hiring the wrong person may mean that hundreds of poor quality tests will be performed before the process of personnel change can be completed. This is no small matter, given that big impact decisions such as the suitability for surgery, need for medications, safety of continuing medical treatment (eg, chemotherapy), and employment eligibility can hinge on pulmonary function data. It is not enough to say that we must act when spurious data are produced as a consequence of technologist incompetence; proactive measures must be undertaken so that poor quality data are never produced. The first and perhaps most important measure to assure quality is to choose the right person to work in the PFT laboratory. ${ }^{10}$

As Lord Kelvin famously said, "When you can measure what you are speaking about, and express it in numbers, you know something about it; but when you cannot measure it, when you cannot express it in numbers, your knowledge is of a meager and unsatisfactory kind." Standardized testing of aptitude and other traits to identify human potential is commonplace. For several decades the military (eg, Armed Services Vocational Aptitude Battery ${ }^{28}$ ), universities (eg, Medical College Admission Test ${ }^{29}$ ), and other industries have used standardized tests to screen their applicants. ${ }^{30}$ Given that the impact of technologist job performance on test results is enormous, the profession should explore the idea of using validated screening tests to ensure that we select only the best candidates to work in the pulmonary function laboratory.

If we accept the idea that objective testing might improve technologist selection, the next obvious question is what kind of traits we should look for in a pulmonary function technologist. While stereotypical traits of a good technologist are those with a "type A" or "perfectionist" personality, there are no data specific to pulmonary function technologists to guide us. I submit that there are at least 3 important measurable traits that a technologist should posses: high cognitive aptitude; conscientiousness; critical thinking skills.

Cognitive aptitude, the ability to learn, is an important trait for transitional stages of work. ${ }^{30}$ Transitional stages of work describes those in which new job tasks must be learned, including both initial training and when new techniques are added to one's job duties. While cognitive aptitude correlates well with job performance in transitional stages of work, higher cognitive aptitude does not predict 
Table 1. Attributes of Individuals With Critical Thinking Skills ${ }^{34}$

Is open-minded and mindful of alternatives

Tries to be well informed

Judges well the credibility of sources

Identifies conclusions, reasons, and assumptions

Judges well the quality of an argument, including the acceptability of its reasons, assumptions, and evidence

Can well develop and defend a reasonable position

Asks appropriate clarifying questions

Formulates plausible hypotheses; plans experiments well

Defines terms in a way appropriate for the context

Draws conclusions when warranted, but with caution

Integrates all items in this list when deciding what to believe or do

good job performance in the maintenance stages of work. 30,31 This is particularly true of "routine tasks," which are a big part of the daily life of a pulmonary function technologist. The personality trait that correlates best with job performance during maintenance stages of work is conscientiousness. ${ }^{30,32,33}$ Workers who score high on the conscientious portion of personality tests are reliable, employ autonomous goal setting, are adept at time management, and exhibit perseverance when confronted with difficult problems. ${ }^{30}$ Conscientiousness is so important to maintenance stages of work that one author wrote, "it is better to be reliable but dumb than smart but slapdash."33 Obviously we don't want to recruit pulmonary function technologists with low cognitive aptitude; however, pulmonary function technologists, no matter how intelligent, must be conscientious.

Lastly, pulmonary function technologists must possess critical thinking skills. Ennis, a leading authority in the field of thought processes, defined critical thinking as "reasonable reflective thinking focused on deciding what to believe or do." 34 Attributes of individuals with critical thinking skills are listed in Table $1 .{ }^{34}$ Critical thinking skills have been shown by some investigators to correlate well with problem solving and clinical decision making. Hill administered the Watson-Glaser Critical Thinking Appraisal to 143 graduating respiratory therapy students from 10 different programs. Students with better critical thinking skills made better clinical decisions when taking the Clinical Simulation Self-Assessment Examination. ${ }^{35}$ Being able to solve problems quickly and independently is a very important trait for a pulmonary function technologist to possess. Very often the pulmonary function technologist will be confronted with oddities during data collection, which can be caused by patient technique, unusual physiology, or instrumentation issues. For example, progressively declining values during spirometry testing can be due to patient fatigue, bronchoconstriction related to deep inspiration, or pneumotachometer dysfunction. Being able to decipher the cause of unusual data patterns and make corrective actions if necessary is what separates a good technologist from someone who knows little more than how and when to push the start, stop, and print buttons. Most importantly, the technologist with excellent critical thinking skills will produce higher quality tests with fewer oddities and more meaningful and consequential data.

Standardized aptitude and personality trait tests are abundant in the marketplace and can even be taken on the Internet. While it may be a safe assumption that smart, conscientious individuals with good critical thinking skills make better pulmonary function technologists, a résumé review and interview may not have the specificity to exclude applicants who do not possess these traits. Studies are needed to assess the effect of cognitive aptitude and personality traits on technologist performance as well as the possible role of standardized testing for technologist selection.

\section{Technologist Training and Maintenance}

\section{Training}

The ATS has suggested that 6-12 months of training are required for technologists to competently perform arterial blood gas analysis, spirometry, lung volume determination, diffusion capacity, and exercise testing. ${ }^{24}$ However, this recommendation was made in 1982, when only a high school diploma was required of trainees. As mentioned earlier, trainees with higher cognitive aptitude and exposure to pulmonary function science in college can be expected to require less training time. ${ }^{24,30}$ Trainees who require more than 6 months of training to perform routine PFTs proficiently may not be well suited for working in the PFT lab.

The content and quality of training are much more important than the time frame. Blonshine ${ }^{36}$ summarized important skills that technologists must master from their training (see Table 2). Table 2 could easily be reformatted as a checklist that managers could use when training new staff and evaluating existing staff members.

The first step in the training process is to become familiar with the day-to-day operations of the laboratory, including the logistics of patient scheduling and physician interpretation. Familiarization with the pulmonary function equipment, including calibration, should precede patient testing. My approach to PFT training is a "one-stepat-a-time" strategy. The trainee should first observe the instructor administering tests; the instructor should take every opportunity to offer insights to teach the learner what constitutes good effort and technique and how to remedy unacceptable effort and technique. Discussions about the normality of test results should be done in private, after the patient has been discharged from the laboratory. The next step is to have the trainee administer tests 


\section{Quality Assurance of the Pulmonary Function Technologist}

Table 2. Skills and Knowledge Required of a Pulmonary Function Technologist ${ }^{36}$

\footnotetext{
Subject preparation for testing

Identification of indications and contraindications for testing

Subject coaching and demonstration of proper testing technique

Identification of test accuracy and validity

Identification of technical problems that may occur during testing and the appropriate responses for problem resolution

Theory associated with each testing maneuver that includes both physiologic and equipment understanding

Recognition of both technical and equipment errors, including submaximal effort

Proper calibration techniques and recognition of out-of-control results

Routine equipment maintenance and troubleshooting

Interpretation of results as normal or abnormal

Patient assessment skills
}

on the instructor or other willing co-workers. Once trainees demonstrate the ability to administer a test correctly, they can begin testing patients with the supervision of the instructor. The instructor should, when necessary, jump in with immediate feedback, and sometimes administer a single testing effort with the patient to demonstrate more effective coaching. Once trainees demonstrate that they can administer spirometry proficiently, the process is repeated with diffusion capacity, then lung volumes. The "one-step-at-a-time" approach allows the trainee to focus on learning how to administer one test at a time while building confidence as the process progresses. Once the trainee can administer all tests proficiently, the instructor observes testing from the back of the room, being available for questions, and should tactfully interrupt testing to offer advice when necessary. Over time the instructor drifts out of the laboratory, while still being available for questions from the trainee. Once routine tests are mastered, more complex tests, such as cardiopulmonary exercise and bronchoprovocation testing, can be introduced. All PFT reports produced by the trainee should be reviewed for many months until the trainee's performance is consistently acceptable. Documentation of competency for each test may be required by your laboratory's regulatory agency. ${ }^{36}$

During the training period the trainee should also be reading pulmonary function testing materials. The ATS/ ERS PFT guidelines ${ }^{11-13,25,37,38}$ which are accessible on the Internet (http://www.thoracic.org/statements/ index.php) without fee, should be read by all trainees. Trainees should read pulmonary function text books such as Ruppel's Manual of Pulmonary Function Testing. ${ }^{39}$ I had the pleasure of reviewing the 9th edition of this book for the Journal. ${ }^{40}$ Each chapter includes learning objectives, interpretative strategies, case studies, and both entrylevel and advanced practitioner end-of-chapter exams. Another helpful resource is the ATS Pulmonary Function

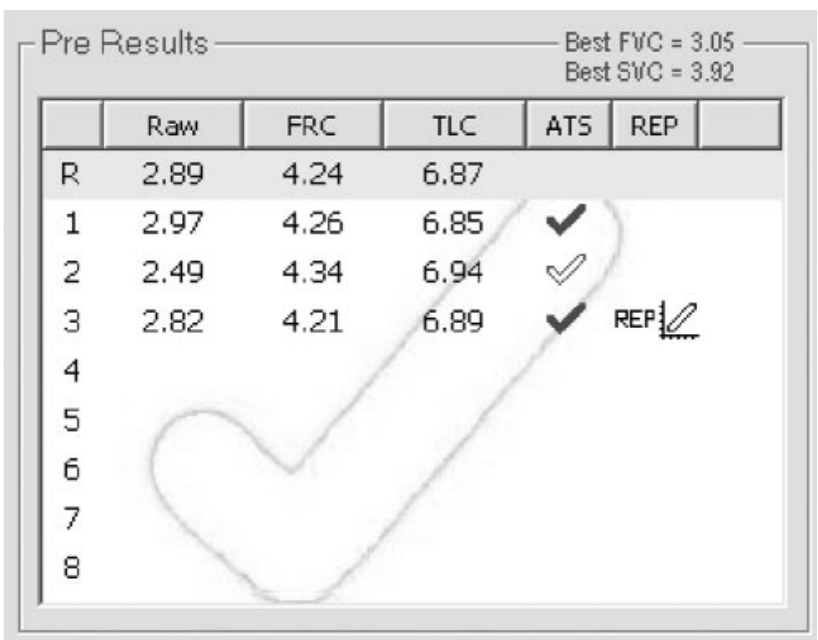

Fig. 1. A snapshot on-screen display of test acceptability and reproducibility. The small check marks indicate effort acceptability, and the large central check mark indicates effort reproducibility (ComPAS, Morgan Scientific, Haverhill, Massachusetts).

Laboratory Management and Procedure Manual (http:// www.thoracic.org/education/pulmonary-function-testing/ index.php). All technologists should be familiar with these important resources. Moreover, all laboratory management and staff should embrace the concept of career-long learning in the never-ending pursuit of excellence.

\section{Test Acceptability and Reproducibility Feedback}

One of the most important advances in PFT systems is instantaneous grading of test adherence to ATS/ERS acceptability and reproducibility standards. This gives the technologist immediate feedback on each test effort's quality, and advice on how to improve the patient's performance (Figs. 1, 2, and 3). Without this innovation, many quality outcomes could not be analyzed between patient efforts, because they are too time-consuming and impractical to calculate by hand (eg, spirometry back-extrapolation volume from a volume-time curve). Technologists should be encouraged to use these types of feedback tools to improve the quality of tests; however, it should be understood that tests meeting computerized acceptability standards are not always the patient's best effort. Patient efforts that meet ATS/ERS acceptability standards despite evidence that the patient's effort or technique are suboptimal should be repeated. Most pulmonary function systems are capable of displaying information regarding the acceptability and reproducibility of tests on the final report. Including this information on the final report aids the physician in interpretation and may motivate some technologists to try harder to adhere to ATS/ERS standards. 


\section{Quality Assurance of the Pulmonary Function Technologist}

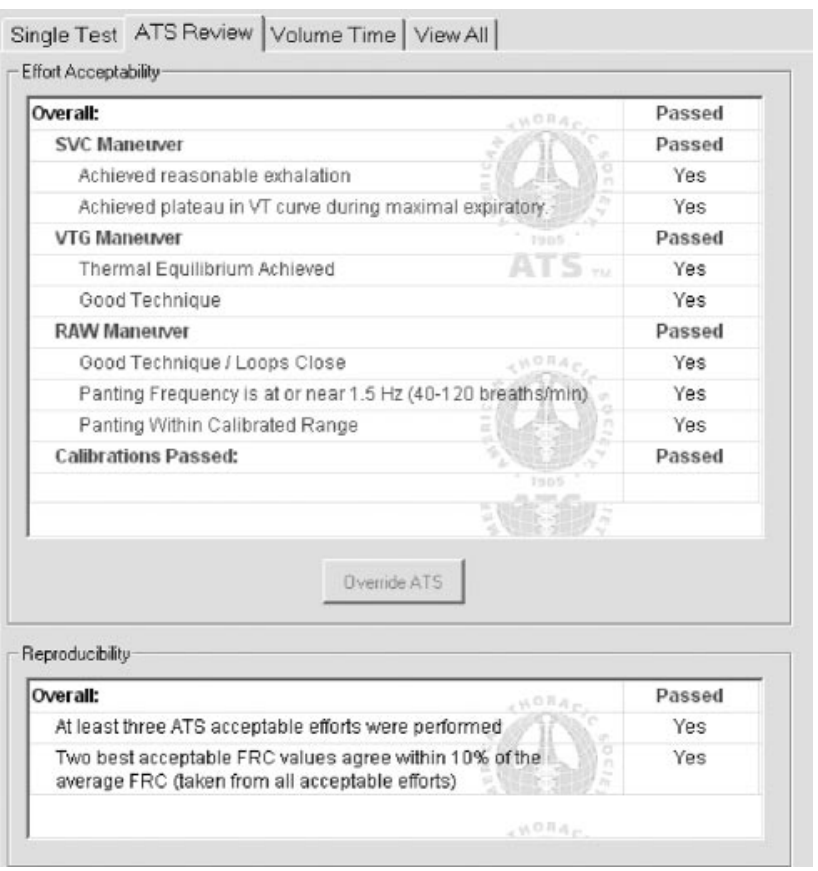

Fig. 2. A more detailed explanation of the pulmonary function data reported in Figure 1 (ComPAS, Morgan Scientific, Haverhill, Massachusetts).

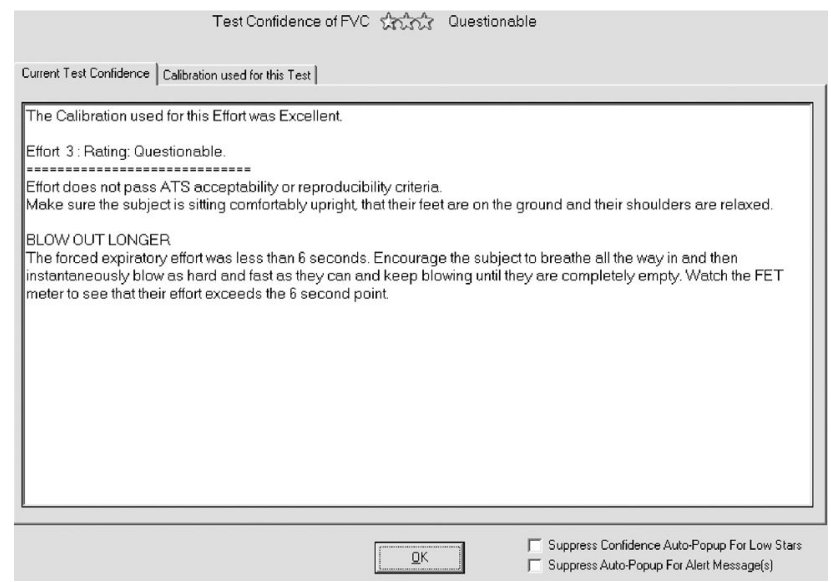

Fig. 3. An example of a quality feedback pop-up window designed to help the technologist improve the quality of testing efforts (ComPAS, Morgan Scientific, Haverhill, Massachusetts).

\section{Technologist Performance Feedbacks}

Probably the most overlooked ATS/ERS PFT standard is the recommendation that a laboratory's quality control program should include the continuous monitoring of technologist performance. ${ }^{25}$ In addition, technologists should regularly be given feedback on their performance (Table 3). ${ }^{25}$ In an informal poll of pulmonary function personnel from around the United States, only $30 \%$ of respondents reported compliance with this recommendation. ${ }^{41}$
Table 3. American Thoracic Society/European Respiratory Society Recommended Performance Feedback for Pulmonary Function Technologists ${ }^{25}$

Information concerning the nature and extent of unacceptable maneuvers and nonreproducible tests

Corrective action that the technician can take to improve the quality and number of acceptable maneuvers

Positive feedback to technicians for good performance

Comments regarding system set-up and reporting results

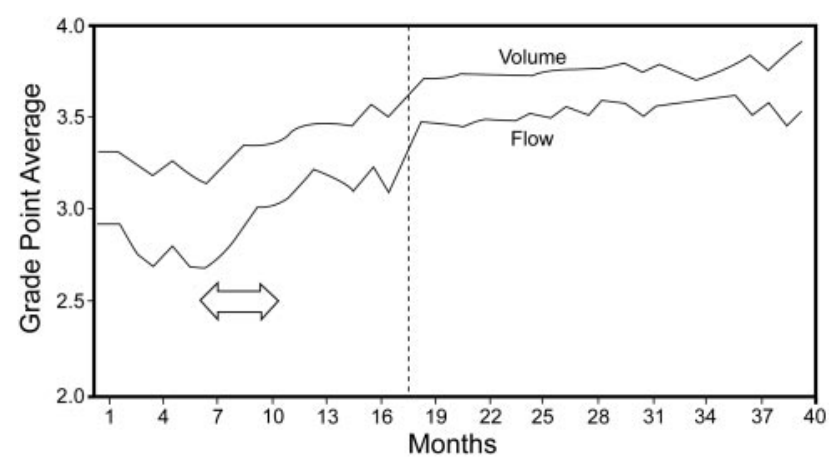

Fig. 4. Spirometry test quality, reported as a grade point average, for the pulmonary function technicians, in the first 40 months of the Lung Health Study. The horizontal arrow indicates the time of site visits by spirometry instructors, for repeat training of spirometry technicians at participating centers. The dashed line indicates the inception of technician monitoring and feedback. (From Reference 41; data from Reference 42.)

Data supporting technologist performance feedback first came from the Lung Health Study. ${ }^{42}$ Enright and his colleagues in the Lung Health Study Research Group documented that spirometry quality progressively declined following technologist training. Technologist performance improved following visits from instructors, but a high level of performance was sustained only after a program of technologist performance feedback was implemented (Fig. 4). Since that time, central monitoring of PFT quality, coupled with technologist feedback and re-training, has become the standard methodology for both clinical and epidemiologic studies, including, but not limited to, the Salute Respiratoria nell' Anziano ${ }^{43}$ (SARA [Respiratory Health in the Elderly]); Projector Latino-Americano de Investigação em Obstrução Pulmonar ${ }^{44}$ (PLATINO); the World Trade Center Worker and Volunteer Medical Screening Program ${ }^{45}$; the Registry for Patients with Severe Alpha-1 Antitrypsin Deficiency ${ }^{46}$; the Children's Health Study ${ }^{47}$; the Bronchitis Randomized on N-Acetylcysteine (NAC) Cost-Utility Study ${ }^{48}$ (BRONCUS); and the Understanding Potential Long-Term Impacts on Function With Tiotropium $^{8}$ (UPLIFT) study. Many of the above mentioned studies reported remarkably good spirometry quality, despite facing substantial challenges. For example, the SARA study collected spirometry data from patients with 


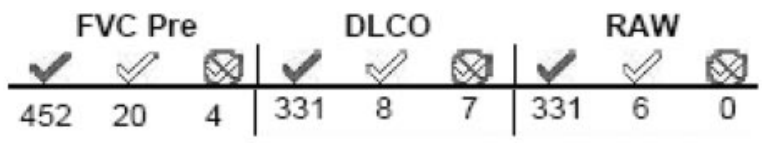

Fig. 5. An example of a technologist proficiency report. The solid check mark indicates the number of tests that meet American Thoracic Society/European Respiratory Society acceptability and reproducibility standards. The open check mark indicates the number of tests that captured acceptable but irreproducible efforts. The check mark with the circle-backslash symbol indicates the number of tests in which no acceptable efforts could be obtained (ComPAS, Morgan Scientific, Haverhill, Massachusetts).

ages ranging from $65-100$ years, and only $20 \%$ of their technicians had previous experience with spirometry testing. Despite these challenges, the SARA investigators reported that $77 \%$ of all subjects produced 3 acceptable spirometry efforts. ${ }^{43}$ The PLATINO investigators reported that $89 \%$ of subjects produced quality spirometry, despite the fact that $73 \%$ of their technicians had no prior experience, and on average the study population had less than 8 years of formal education. ${ }^{44}$ In addition, technologist oversight and feedback has also been shown to improve the quality of office spirometry ${ }^{49}$ and bedside spirometry in a hospital setting. ${ }^{26}$

Surprisingly, there are no data evaluating the effects of technologist oversight and feedback on the performance of technologists in a PFT laboratory. In my own laboratory we observed a $21 \%$ increase in the percentage of spirometry tests that met ATS/ERS acceptability and reproducibility standards following the inception of a quality assurance program modeled after the Lung Health Study (unpublished data). Many modern PFT systems make technologist-performance data easy to retrieve and analyze (Fig. 5). If a laboratory's pulmonary function system software does not include technologist performance reporting, the Spirometry Longitudinal Data Analysis Software (SPIROLA) can be downloaded from the Centers for Disease Control and Prevention Internet site, without fee. ${ }^{50,51} \mathrm{Cen}-$ tralized monitoring of PFT quality, coupled with technologist feedback, improves PFT quality.

The only cautionary note regarding a technologist feedback program is that there is the potential for some technologists to delete valuable data when acceptability or reproducibility criteria cannot be met (ie, opting to report that the patient could not perform the test), in order to avoid any negative impact on their performance statistics. Ironically, this type of action violates the very standards that the technologist performance statistics are intended to promote. ${ }^{11}$ In addition, the Global Lungs Initiative phase 2 pilot study shows that spirometry data with less than grade $\mathrm{A}$ reproducibility scores were still valid and had a trivial effect on the formulation of predicted values. ${ }^{52}$ Moreover, some technologists in the pursuit of higher performance scores may push patients to unreasonable limits (eg, $>12$ spirometry efforts). For these reasons it is important to stress to all technologists that, while performance statistics are important, they should not be the solitary focus of one's work. Setting reasonable performance goals, providing educational support, offering positive feedback for good performance, and avoiding hyperbolic criticism are part of a healthy environment for technologists and patients.

Enright and colleagues ${ }^{19}$ have suggested $90 \%$ of spirometry tests should meet ATS/ERS acceptability and reproducibility criteria; I am aware of no data regarding acceptability/reproducibility goals for other PFTs. Three technologists work in my laboratory; the percentage of tests meeting ATS/ERS acceptability and reproducibility criteria for the year 2010 are as follows: spirometry $=93 \%$; single-breath diffusion capacity $=93 \%$; plethysmographic lung volume/airway resistance $=96 \%$. I submit that a goal of $\geq 90 \%$ ATS/ERS compliance for the above mentioned tests is both appropriate and achievable.

\section{Laboratory Accreditation}

On November 2, 1987, The Wall Street Journal published an article by investigative reporter Walt Bogdanich, exposing an excessive number of false-negative Papanicolaou (Pap) smear tests performed in clinics. ${ }^{53}$ The socalled "Pap mills" used poorly trained, overworked personnel and haphazard laboratory practices, and an unconscionable number of women suffered the consequences. The scandal that ensued led to expanded regulatory powers of the Clinical Laboratory Improvement Amendments (CLIA), which increased the scope of laboratory oversight and accreditation. At the time of this writing, mandatory or voluntary accreditation schemes exist for virtually every laboratory environment in the medical, dental, and veterinary fields. However, in the United States and throughout most of the world, pulmonary function laboratories are not subject to mandatory accreditation, nor does the opportunity for voluntary accreditation even exist. Pulmonary function laboratory accreditation is available in the Canadian Provinces of Alberta, British Columbia, and Ontario; New Zealand; and Australia. ${ }^{54}$ Accreditation by the Thoracic Society of Australia and New Zealand is mandatory for any centers operating as a training facility (http://www.thoracic.org.au).

It is hard to explain why it has taken so long for accreditation of pulmonary function laboratories to come to fruition. The much younger field of sleep medicine has offered laboratory accreditation since 1977. ${ }^{55}$ Laboratory accreditation improves the quality of diagnostics through education and the verification of compliance with best laboratory practices. Without laboratory inspection and accreditation, physicians and patients can only be hopeful that the laboratories they depend on are operated safely and competently. While most, if not all, pulmonary func- 


\section{Quality Assurance of the Pulmonary Function Technologist}

Table 4. Key Components of Pulmonary Function Laboratory Accreditation, as Proposed by the World Lung Function Accreditation Project

Appropriately trained staff (with qualifications where possible) Complete departmental operating manual (based on American Thoracic Society/European Respiratory Society standards) Robust quality control procedures, with evidence of regular checks Reliable and accurate lung function equipment with up-to-date maintenance logs

tion technologists will purport that their testing practices are compliant with ATS/ERS guidelines, most do not follow the recommendation of weekly biologic controls of diffusion capacity testing ${ }^{54}$ or provide the recommended feedback to technologists regarding their performance. ${ }^{41} \mathrm{It}$ is therefore logical to assume that many other recommendations are also not followed.

In 2007 the World Lung Function Accreditation Project (WOLFAP) was initiated to work toward the goal of assuring quality pulmonary function testing throughout the world (http://www.lungfunction.org/wolfap.html). Unfortunately, WOLFAP has not advanced much since its inception; however, key components of an accreditation process have been developed by WOLFAP. The proposed components of WOLFAP accreditation are listed in Table 4 . Internationally agreed upon accreditation standards brings the talents of the world's top experts into the process and reduces the influence of variations in laboratory practices on the interpretation of data derived from international and multinational research studies. Mandatory accreditation for all pulmonary function laboratories in the United States would likely be the most effective strategy, since those with the most deficient laboratory practices are not likely to voluntarily subject themselves to inspection. Pulmonary function technologists and physicians involved in pulmonary function testing and research should be the strongest advocates for pulmonary function laboratory accreditation.

\section{Summary}

The skill and work habits of the pulmonary function technologist are central to the quality of patient testing. Pulmonary function technologists should be chosen carefully. The pulmonary function technologists must be intelligent, conscientious, and possess critical thinking skills. Studies are needed to better identify which kinds of personality traits correlate with superior job performance, and whether or not such traits can be reliably identified by standardized testing. Monitoring of technologist performance and technologist feedback improves the quality of testing, but is only utilized by a minority of clinical laboratories. Pulmonary function laboratory accreditation is urgently needed to protect the public from potential misdiagnosis and inappropriate treatment due to spurious data.

\section{REFERENCES}

1. Franklin W, Michelson AL, Lowell FC, Schiller IW. Clinical value of a tracing of forced expiration (expirogram). I. Pulmonary disease. N Engl J Med 1955;253(19):799-808.

2. Gaensler EA. Air velocity index; a numerical expression of the functionally effective portion of ventilation. Am Rev Tuberc 1950;62(1A):17-28.

3. March HW, Lyons HA. A study of the maximal ventilatory flow rates in health and disease. Chest 1960;37:602-614.

4. Eisner MD. Environmental tobacco smoke exposure and pulmonary function among adults in NHANES III: impact on the general population and adults with current asthma. Environ Health Perspect 2002;110(8):765-770.

5. Lee HM, Chung SJ, Lopez VA, Wong ND. Association of FVC and total mortality in US adults with metabolic syndrome and diabetes. Chest. 136(1):171-176.

6. Fletcher C, Peto R. The natural history of chronic airflow obstruction. Br Med J 1977;1(6077):1645-1648.

7. Anthonisen NR, Connett JE, Kely JP, Altose MD, Bailey WC, Buist AS, et al. Effects of smoking intervention and the use of an inhaled anticholinergic bronchodilator on the rate of decline of $\mathrm{FEV}_{1}$. The Lung Health Study. JAMA 1994;272(19):1497-1505.

8. Tashkin DP, Celli B, Senn S, Burkhart D, Kesten S, Menjoge S, Decramer M; UPLIFT Study Investigators. A 4-year trial of tiotropium in chronic obstructive pulmonary disease. N Engl J Med 2008; 359(15):1543-1554.

9. Holt EW, Tan J, Hosgood HD. The impact of spirometry on pediatric asthma diagnosis and treatment. J Asthma 2006;43(7):489-493.

10. Wanger J. Quality assurance. Respir Care Clin N Am 1997;3(2): 273-289.

11. Miller MR, Hankinson J, Brusasco V, Burgos F, Cassaburi R, Coates A. et al. Standardisation of spirometry. Eur Respir J 2005;26(2):319-338.

12. Wanger J, Clausen JL, Coates A, Pedersen OF, Brusasco V, Burgos F, et al. Standardisation of the measurement of lung volumes. Eur Respir J 2005;26(3):511-522.

13. MacIntyre N, Crapo RO, Viegi G, Johnson DC, van der Grinten CP, Brusasco V, et al. Standardisation of the single-breath determination of carbon monoxide uptake in the lung. Eur Respir J 2005;26(4): 720-735.

14. Aguilar-Fernández AJ, Villa-Asensi JR, Castro-Codesal M, Almeria-Gil E, González-Alvarez MI, Romero-Andújar F. Concordance between the Piko-1 portable device and pneumotachography in measuring PEF and $\mathrm{FEV}_{1}$ in asthmatic children. Allergol Immunopathol (Madr) 2009;37(5):244-248.

15. Maree DM, Videler EA, Hallauer M, Pieper CH, Bolliger CT. Comparison of a new desktop spirometer (Diagnosa) with a laboratory spirometer. Respiration 2001;68(4):400-404.

16. Swart F, Schuurmans MM, Heydenreich JC, Pieper CH, Bolliger CT. Comparison of a new desktop spirometer (Spirospec) with a laboratory spirometer in a respiratory out-patient clinic. Respir Care 2003;48(6):591-595.

17. Liistro G, Vanwelde C, Vincken W, Vandevoorde J, Verleden G, Buffels $\mathrm{J}$; on behalf of the COPD Advisory Board. Technical and functional assessment of 10 office spirometers. A multicenter comparative study. Chest. 2006;130(3):657-665.

18. Brouwer AF, Roorda RJ, Brand PL. Comparison between peak expiratory flow and $\mathrm{FEV}_{1}$ measurements on a home spirometer and on a pneumotachograph in children with asthma. Pediatr Pulmonol 2007; 42(9):813-818. 


\section{Quality Assurance of the Pulmonary Function Technologist}

19. Enright PL, Beck KC, Sherrill DL. Repeatability of spirometry in 18,000 adult patients. Am J Respir Crit Care Med 2004;169(2):235-238.

20. Hastings JK, West DS, Hong SH. Changes in pharmacy student motivation during progression through the curriculum. Am J Pharm Educ 2005;69(2):251-255.

21. Dompnier B, Darnon C, Butera F. Faking the desire to learn: a clarification of the link between mastery goals and academic achievement. Psychol Sci 2009;20(8):939-943.

22. Woolf CR. Organization of a hospital routine pulmonary function laboratory. Can Med Assoc J 1968;98(11):542-549.

23. Hughes DT, Empey DW. Ten years' experience in running a pulmonary function laboratory. Br Med J 1972;4(5838):470-473.

24. Gardner RM, Clausen JL, Epler G, Hankinson JL, Permutt S, Plummer AL. Pulmonary function laboratory personnel qualifications. Am Rev Respir Dis 1986;134(3):623-624

25. Miller MR, Crapo R, Hankinson J, Brusasco V, Burgos F, Casaburi $\mathrm{R}$, et al. General considerations for lung function testing. Eur Respir J 2005;26(1):153-161.

26. Stoller JK, Orens DK, Hoisington E, McCarthy K. Bedside spirometry in a tertiary care hospital: the Cleveland Clinic experience. Respir Care 2002;47(5):578-582.

27. Stoller JK, Orens DK, Kester L. The impact of turnover among respiratory care practitioners in a health care system: frequency and associated costs. Respir Care 2001;46(3):238-242.

28. Carretta TR, King RE. Improved military air traffic controller selection methods as measured by subsequent training performance. Aviat Space Environ Med 2008;79(1):36-43.

29. Julian ER. Validity of the Medical College Admission Test for predicting medical school performance. Acad Med 2005;80(10):910917.

30. Thoresen CJ, Bradley JC, Bliese PD, Thoresen JD. The big five personality traits and individual job performance: growth trajectories in maintenance and transitional job stages. J Appl Psychol 2004; 89(5):835-853.

31. Keil CT, Cortina JM. Degradation of validity over time: a test and extension of Ackerman's model. Psychol Bull 2001;127(5):673-697.

32. Kern ML, Friedman HS, Martin LR, Reynolds CA, Luong G. Conscientiousness, career success, and longevity: a lifespan analysis. Ann Behav Med 2009;37(2):154-163.

33. Charlton BG. Why it is 'better' to be reliable but dumb than smart but slapdash: are intelligence (IQ) and conscientiousness best regarded as gifts or virtues? Med Hypotheses 2009;73(4):465-467.

34. Ennis RH. A super-streamlined conception of critical thinking. http:// faculty.ed.uiuc.edu/rhennis/SSConcCTApr3.html. June 20, 2002. Accessed November 2, 2011.

35. Hill TV. The relationship between critical thinking and decision-making in respiratory care students. Respir Care 2002;47(5):571-577.

36. Blonshine $\mathrm{S}$. Integrating education with diagnostics, patient and technologist. Respir Care Clin N Am 1997;3(2):139-154.

37. Pellegrino R, Viegi G, Brusasco V, Crapo RO, Burgos F, Casaburi $\mathrm{R}$, et al. Interpretative strategies for lung function tests. Eur Respir J 2005;26(5):948-968.

38. Crapo RO, Casaburi R, Coates AL, Enright PL, Hankinson JL, Irvin CG, et al. Guidelines for methacholine and exercise challenge testing-1999. This official statement of the American Thoracic Society was adopted by the ATS Board of Directors, July 1999. Am J Respir Crit Care Med 2000;161(1):309-329.

39. Ruppel GL. Manual of pulmonary function testing, 9th edition. St. Louis: Mosby/Elsevier; 2009.

40. Haynes JM. Review of the book Manual of pulmonary function testing, by Ruppel GL, 9th edition. Respir Care 2009;54(3):403-404

41. Haynes JM. Comprehensive quality control for pulmonary function testing: it's time to face the music (editorial). Respir Care 2010; 55(3):355-357.

42. Enright PL, Johnson LR, Connett JE, Voelker H, Buist AS. Spirometry in the lung health study. 1. Methods and quality control. Am Rev Respir Dis 1990;143(6):1215-1223.

43. Bellia V, Pistelli R, Catalano F, Antonelli-Incalzi R, Grassi V, Meillo G, et al. Quality control of spirometry in the elderly: the SARA study. Am J Respir Crit Care Med 2000;161(4 Pt 1):1094-1100.

44. Pérez-Padilla R, Vázquez-García JC, Márquez MN, Menezes AM; the PLATINO Group. Spirometry quality-control strategies in a multinational study of the prevalence of chronic obstructive pulmonary disease. Respir Care 2008;53(8):1019-1026

45. Enright PL, Skloot GS, Cox-Ganser JM, Udasin IG, Herbert R. Quality of spirometry performed by 13,599 participants in the world trade center worker and volunteer medical screening program. Respir Care 2010;55(3):303-309.

46. Stoller JK, Buist AS, Burrows B, Crystal RG, Fallat RJ, McCarthy $\mathrm{K}$, et al; the alpha-1 Antitrypsin Deficiency Registry Study Group. Quality control of spirometry testing in the registry for patients with severe alpha-1 antitrypsin deficiency. Chest 1997;111(4):899-909.

47. Enright PL, Linn WS, Avol EL, Margolis HG, Gong H, Peters JM. Quality of spirometry test performance in children and adolescents: experience in a large field study. Chest 2000;118(3):665-671.

48. Pellegrino R, Decramer M, van Schayck CP, Dekhuijzen PN, Troosters $\mathrm{T}$, van Herwaarden C, et al. Quality control of spirometry: a lesson from the BRONCUS trial. Eur Respir J 2005;26(6):1104-1109.

49. Eaton T, Withy S, Garrett JE, Mercer J, Whitlock RM, Rea HH. Spirometry in primary care practice: The importance of quality assurance and the impact of spirometry workshops. Chest 1999;116(2):416-423.

50. Hnizdo E, Yan T, Hakobyan A, Enright P, Beeckman-Wagner L, Hankinson J, et al. Spirometry longitudinal data analysis software (SPIROLA) for analysis of spirometry data in workplace prevention or COPD treatment. Open Med Inform J 2010;8(4):94-102.

51. Spirometry Longitudinal Data Analysis (SPIROLA) Software. http:// www.cdc.gov/niosh/topics/spirometry/spirola-software.html. Accessed November 2, 2011

52. Stock J. ERS Global Lungs Initiative: progress to date. GLI Network meeting, ERS congress, Amsterdam 2011. http://www.lungfunction. org/ers \%20gli \%20\%20meeting_amsterdam_25sep2011_combined \%20presentations.pdf. Accessed February 8, 2011.

53. Bogdanich W. Lax laboratories: the Pap test misses much cervical cancer through labs' errors. The Wall Street Journal; November 2, 1987.

54. Enright P, Swanney MP. A worldwide program of PFT laboratory accreditation is needed. RT Magazine, February 2007.

55. Carlin BW. Sleep medicine certification and accreditation. Respir Care 2010;55(10):1377-1385.

\section{Discussion}

Coates: One thing that I would suggest that's also extremely important in the smooth running of PFT labs is an active role of the medical di- rector. It's one thing to say that this test wasn't appropriate or didn't meet standards, but it's something quite different to go into the lab and point out carefully to the technician why this didn't happen and what could be done to do it a little better. This must not instill an air of intimidation and fear, but rather create a feeling throughout the lab that the medical director is there to help people. 
Haynes: Yes, I agree, and I think there's also a role for a chief PFT technologist in laboratory oversight and leadership. The down side of depending solely on the medical director is that they're very busy: it's not always easy to get them into the lab. We do have a communication mechanism in our lab, which I think was part of the Lung Health Study ${ }^{1}$ program, a message board for our medical director and all of our interpreting physicians to contact us about specific tests and problems. You're right; you do have to have a supportive atmosphere. It's been my experience that the chief PFT technologist is probably more accessible for leadership and oversight.

1. Enright PL, Johnson LR, Connett JE, Voelker H, Buist AS. Spirometry in the Lung Health Study. 1. Methods and quality control. Am Rev Respir Dis 1990;143(6): 1215-1223.

Coates: Absolutely. The other issue that we talked a little bit about yesterday is that when you start to talk about small people and especially children, the ATS/ERS criteria ${ }^{1}$ for repeatability and acceptability of single tests are probably much more permissive, and what is frequently achieved is much tighter. Again, it doesn't matter if the computer gives you a check that says you met a certain quality assurance. Nothing can be better than looking closely at the tracing and saying, "I can do better than that."

The example is a back-extrapolated volume in the 2005 document is $150 \mathrm{~mL}$, but shortly after that came out, Paul Aurora suggested ${ }^{2}$ that it be lowered to $80 \mathrm{~mL}$ for small children, which I think would be much more appropriate. The field is evolving, but good technicians had already achieved that, because they would look closely at the tracing and say, "I know it meets criteria, but I can do better than that." And, again, that needs a very encouraging, supportive atmosphere in which the chief technician-as well as the medical director-plays a role.
1. Miller MR, Hankinson J, Brusasco V, Burgos F, Casaburi R, Coates A, et al; ATS/ ERS Task Force. Standardisation of spirometry. Eur Respir J 2005;26(2):319-338.

2. Kozlowska WJ, Aurora P. Spirometry in the pre-school age group. Paediatr Respir Rev 2005;6(4):267-272.

Haynes: Yes, I agree completely. I routinely discard efforts that satisfy ATS/ERS acceptability via computerized grading. I will very often discard flow-volume loops that are just "OK" because the peak expiratory flow affects the validity of the $\mathrm{FEV}_{1}$ due to compression of thoracic gas. Technologists should be harder to satisfy than the computer.

Salzman: I think that it's a good point that personality characteristics like conscientiousness are very important. On the other hand, there is a definite mathematical, graphic, cognitive component to this. In some of my interviewing, what I've done, in the guise of getting them familiar with the particular equipment that we have, I've taken people I' $m$ interviewing over to the equipment and I start showing them some curves and try to get some reactions out of them-“"Take a look at this: how would you interpret this?"just to see if are they really familiar with looking at the data other than was it flagged with an error code or not. I've been surprised often at how, shockingly, candidates for PFT tech jobs were unable to look at the curves critically.

Haynes: Shocking is the word I was going to use as well. I think that's why I would prefer to see someone come into my lab with the RPFT [registered pulmonary function technician] credential. That's a starting point, but clearly we can't assume that anyone who walks into your lab with or without a credential is competent. The same applies to experience; an individual may boast that they have 25 years of experience, but in reality they've used those years to become really good at doing tests very poorly. We have to assure that testing is done the way that we would want it done.

Miller: I was waiting for the shocking part of the discussion. I'd like to repeat what I said yesterday and bring up this question of whether we should de-recommend handheld or other spirometers that only measure on expiration, where you cannot assure that you have reached full inspiration. You could monitor the expiration and be sure about early termination of effort, brisk onset of exhalation, and reproducibility, but you can't tell if the patient has reached total lung capacity.

The other shocking thing is you gave a long list of large trials, all of which were marked by excellent performance by the techs and excellent data. One of them I'm quite familiar with is the World Trade Center worker and volunteer medical screening program. ${ }^{1} \mathrm{I}$ walked into this program that had been in existence and functioning for several years, and now the first pulmonologist entered the program which had been run by occupational physicians and uncovers every single technical mishap that can be achieved by a tech who went through whatever 3-day program to train and certify. Half the efforts were not acceptable using standard quality assurance checks, and full inspiration was not confirmable.

The technician needs feedback constantly. Within a few weeks of pointing out and watching and encouraging, we could bring the technique up to quality standards. I'm sure among that long list of trials there were similar examples where there were months and years where the data were not acceptable, whatever the computer said, or the computer was ignored or even turned off.

1. Enright P, Skloot G, Herbert R. Standardization of spirometry in assessment of responders following man-made disasters: World Trade Center volunteer medical screening program. Mt Sinai J Med 2008; 75(2):109-114. 
Haynes: In the PLATINO study, ${ }^{1}$ the people responsible for quality oversight sent a lot of their technologists back to the patient to repeat spirometry, and that was one of the reasons why they had such good data. I agree, but I would say that there are some technologists who just are never going to get it, and that's why I'm interested in identifying those people who are both intelligent and conscientious. There are certain technicians who I've worked with in the past who are just super at it. Their effort and quality never changes; it's always good. Those are the people we need to have doing the tests. Not everyone can be a surgeon, no matter how much training you give them, no matter how much feedback you give them. The same applies to pulmonary function technologists. I'm really interested in exploring the idea of who's really fit for doing this. Obviously, it's more difficult in clinical trials to shuffle people out, but if you're in a small lab with 2 or 3 positions, it's your duty to your patients to make sure that the people doing those tests are reliable and competent.

1. Pérez-Padilla R, Vázquez-García JC, Márquez MN, Jardim JR, Pertuzé J, Lisboa $\mathrm{C}$, et al; the Latin American COPD Prevalence Study (PLATINO) Team. The longterm stability of portable spirometers used in a multinational study of the prevalence of chronic obstructive pulmonary disease. Respir Care 2006;51(10):1167-1171.

Hnatiuk: Jeff, I'd like to second the call for doing away with spirometers that don't display the inspiratory loop. I think that's a big problem that can be easily corrected. The other thing that I would like to mention is that we, as physicians, don't train and get involved in the PFT lab like we once did. This is just my opinion, as a prior program director. I believe that it is very important to have a medical director who is interested in his PFT lab. Of course, with or without this, having a good chief technician is critical. But people become PFT lab med- ical directors for a number of reasons. A lot of times it's not their first choice, or even their third choice. I can tell you that in the fellowship curriculum for pulmonologists there is not a lot of attention given on how to direct a PFT lab, or, for that matter, a bronchoscopy suite. A lot of the feedback we received at the 1-year and 5-year mark was, "You didn't do enough to prepare me to run a PFT lab."

Haynes: I think that's a great point, our medical director is our senior pulmonologist, who has more hands-on experience in our lab. Many years ago the medical director would choose which equipment we would purchase. It does seem that the younger generation of pulmonologists have had less exposure to the day-to-day operation of a PFT laboratory.

MacIntyre: I'd like to go back to some of the things Al [Miller] started to bring up, and that is I'm concerned that we're creating a 2-tier system. We all sit here and talk about the high quality we expect from our labs and the standards we've espoused for the techs, but there's this other world out there that thinks we can do spirometry in offices and workplaces and WalMart parking lots. I heard yesterday that one manufacturer has now come up with a diffusing capacity system that can be "portable."

\section{Haynes: God help us.}

MacIntyre: Yeah, but the point isand I've been on the ATS committee for a number of years, and we've certainly wrestled with this-should the standards for office spirometry be different than the standards for lab spirometry? Now it sounds like the standards for office diffusion are going to be different than in the lab, and I think this is bad. I applaud Steve Nelson and the AARC [American Association for Respiratory Care] for trying to put some sense into these issues by coming up with this so-called "spi- rometry driver's license." This certainly is a step in the right direction. I don't want to play it down too much. But, on the other hand, what other test do we do in medicine that has this kind of 2-tiered system, where we expect different standards and have different expectations for what's done out in the field versus what's done in the hospital? We're asking the physician to make the same decisions on those data, and yet in one situation it's crummy or lower quality data than the other.

Haynes: Different standards for hospitals and clinics led to the passage of CLIA in 1988. Prior to CLIA, laboratory standards for Pap [Papanicolaou] smear testing were excellent in hospitals, but clinics and offices weren't held to the same standards. In 1987, Walter Bogdanich from The Wall Street Journal exposed the haphazard laboratory practices in clinics that led to an exorbitant number of false negative Pap smear tests. ${ }^{1}$ An unconscionable number of women suffered the consequences, and this problem was corrected by the expansion of hospital standards to clinics and offices.

1. Bogdanich W. Lax laboratories: the Pap test misses much cervical cancer through labs' errors. The Wall Street Journal; November 2,1987

MacIntyre: You raise the point, people are going to be making judgment about whether to continue chemotherapy or whatever based on these tests that may be done out in the field that don't meet any kind of standards. I'll be really bold, I'm not so sure anybody should do any kind of PFT without being accredited at the level of a lab in a hospital. I'll probably get a lot of things thrown at me for this.

Haynes: I agree with you. I'm not a quitter; if I start something, I will do everything in my power to see it accomplished, but the dream of quality office spirometry is an area that I'm 
almost ready to throw in the towel. There doesn't seem to be a good remedy for obtaining quality pulmonary function data from offices; maybe someone will develop a blood test that can correlate very well with FVC and $\mathrm{FEV}_{1}$. That's our only hope.

MacIntyre: There'd probably still be 2 standards: the one in the physician's office and the one in the lab.

Enright: There is an answer: it's all about the money. Don't pay for bad quality tests! I won't be able to publish the data, but I've been involved in a project where initially only $60 \%$ of the tests done at 300 sites across the United States (primarily in occupational and primary care settings) met the ATS goals for quality. ${ }^{1}$ A legal contract then stipulated payment only for spirometry tests that met ATS quality goals. Very quickly, the spirometry quality from the same providers increased $96 \%$, meeting the quality goals, and has persisted in the high 90s ever since.

1. Miller MR, Hankinson J, Brusasco V, Burgos F, Casaburi R, Coates A, et al; ATS/ ERS Task Force. Standardisation of spirometry. Eur Respir J 2005;26(2):319-338.

Miller: Paul, if I could attempt to answer that question. We're talking about 2 different inspirations. The one you just cited is a full inspiratory flowvolume loop for evaluating upper airway patency; it is a diagnostic test and full attention should be given it. The other inspiration is the one the patient takes to initiate her maximum expiration and produce all those spirometric numbers.

The very thing I was talking about is the spirometer used for the World Trade Center program, which gives a very nice inspiratory loop following the exhalation, so you can assess upper airways dysfunction. But the way the techs often use it is a problem. They could monitor inspiration and start the instrument timing during the inspiratory loop, and that gives you some assurance you reach total lung capacity, but they weren't doing so. They were using it exactly like one of those expiratory-only spirometers where, "take a deep breath in, wait until you manage to get that thing in your mouth," and you see people changing the volumes of their chest as they're doing so, "and then blow out." So I think that we should really be concerned about the one thing we cannot monitor: are we reaching full inspiration? I would like to see tidal volumes in a nice row with a stable baseline, then an inspiration from there, and I would feel much more secure.

Haynes: I couldn't agree more. Technologists must evaluate the inspiratory loop because partial inspiration prior to forced exhalation is the hardest thing to control for. If the patient breathes in partially and blows forcibly, you will indeed see the patient's eyes bulging out of their skull and their face turning red and they may exhale for 6 seconds. This can appear to be great technique. However, the observation that the inspiratory loop exceeds the expiratory staring point on the $\mathrm{X}$ axis will alert you that the patient didn't inhale to total lung capacity prior to forced exhalation.

Pichurko: My concerns for the quality of the final product extend even to those settings where the lab is perfect and the staff is perfectly trained, and it has to do with the kind of patient who is referred. Everyone who has worked in this arena knows that patients with impaired cognition are for many reasons not well suited, will be referred, often as a last-ditch effort by a physician, to find out something useful on why a patient is dyspneic. My question is, what is the role of the PFT lab and its medical director to address the hospital's medical staff, either in the form of grand rounds or whatever is suitable in a particular hos- pital, to educate them about what services we provide and who is a suitable patient to refer to our lab for service?

Haynes: I would say that the ability of a technologist or a doctor to say, "this patient won't be able to do a PFT" is not very good. As shown in the SARA study, ${ }^{1}$ people $65-100$ years old are able to do these tests most of the time. My approach is that if the patient is someone who won't even be able to put the mouthpiece in their mouth, I'll say, “This isn't an appropriate patient." Otherwise I'll give it a try. I can tell you that I bring a lot of elderly people down to the lab who some would say that, "they're never going to be able do it," and I get them to do it correctly.

Changing your approach, instead of only explaining the instructions, I instruct the patient to, "just do what I do," and I raise my hands up and then blow down and the patient mimics my body language. Even if you only capture a couple spirograms, you can get data that are useful. There have been a number of occasions when another technologist has reported that a patient tried but couldn't perform spirometry. and because the data were important for the management of the patient, I have retested the patient using the "mimicking approach" and have successfully obtained quality data.

1. Pistelli R, Bellia V, Catalano F, Antonelli Incalzi R, Scichilone N, Rengo F; SARA Study Group. Spirometry reference values for women and men aged 65-85 living in southern Europe: the effect of health outcomes. Respiration 2003;70(5):484-489.

Coates: I'd like to go back to what we were talking about with the medical directors, and there are some side effects from having a very good chief technician. We have an excellent chief technician who is gaining international recognition. She has been recruited by the SpiroTrec program [http:// www.resptrec.org/spirotrec.php], she's been recruited to help NHANES 
[National Health and Nutrition Examination Survey] IV and Statistics Canada to help with their training to do kids as low as 6 years of age. The very troublesome side effect of this is that our trainees believe that PFTs are always good and they rarely see a poor quality test because there's a level of screening before it gets to them. As a result, when they do a rotation through our PFT lab, they don't really take it all that seriously.

One of them was pretty insightful. He'd just taken a job where he was going to be the only pediatric respiratory physician in the entire province, and he suddenly looked at his training and asked, "Can I spend my last month of training working as a PFT technician?" Which I thought showed a lot of insight because he realized that he had not appropriately prepared himself to be the medical director of a PFT lab. I don't think we've addressed this at all in our curriculum in the way that we should. There's excellent PFT happening in the academic centers where they're driven by highly motivated people, but get outside of that and the medical direction is often appalling.

Salzman: I wanted to make a follow-up point about that, and maybe we could talk about what the precise role of the medical director should be in terms of these quality issues. I wanted to mention a survey I had done with an ACCP [American College of Chest Physicians] group that was published in Chest, looking at the quality of training for pulmonary fellows in pulmonary physiology. Our expectation was that people like this group here would be more critical of the current training of pulmonary fellows because we were trained in the golden era of pulmonary physiology and we understand that the current trainees are going to have a more diverse group of things they need to learn about: bron- choscopy, critical care, sleep, et cetera. But, interestingly, what we actually found was that the younger people were, the closer they were to their training, the more dissatisfied they were with their training in pulmonary physiology. Clearly, there's recognition amongst trainees that they're not getting what they need to know about pulmonary function and pulmonary physiology.

To bring it to a more practical level, what's the best way for the medical director to interact with the PFT techs to get quality to improve? I find that I do 2 sorts of things: one is that when I'm looking at a PFT I'm not happy with, I bring it directly back to that tech and point out the precise things that I thought were done suboptimally. I try to do it in a supportive way. The other thing I try to do is have a monthly conference, which usually gets cancelled because I have a bronchoscopy or a patient to see, but an intermittent PFT case conference where I can go over a series of cases. But sometimes people are drifting off by the second or third case. How do we structure this medical supervision so that the quality is pushed upward?

Ruppel: I wanted to comment on something Bo [Pichurko] brought up about patients who really can't do an acceptable test. In our patient population there are $10-15 \%$ in whom, no matter how hard you try and how good the tech is, the data are probably questionable. If you go into our lab and ask the technologists what the motto of the lab is they'll say, "Bad data are worse than no data." They routinely get comments from me like, "Why did you put these data on the patient's chart?" We see a lot of in-patients who are neurologically impaired or have other problems; you can do spirometry on them, but it's probably a disservice to report those data if the data quality is not very good. Our medical director supports that, but it's a very difficult situation, because the house officers will many times re-order the patient to have the same thing the next day because the results weren't what they expected.

Kaminsky: In line with what Steve [Salzman] was saying regarding education, I think on the respiratory therapy side, too, there's so much for them to learn, especially now, with fancy mechanical ventilators and different aerosolized therapies, and so on. In our small RT school the students rotate through the PFT lab and there's so much to learn. A lot of the teaching comes from the techs and from me when I happen to be around. This extends to medical students and primary care physicians in particular, and I think that's one of the reasons why I don't know the best answer to this hospital spirometry versus office spirometry issue that's been raised.

Ideally, patients who are short of breath who have other symptoms should have spirometry some place. If they're referred to the hospital, we all think that's wonderful because we think we can give them good quality testing. But there are situations, especially in rural areas like where we are in Vermont, where some practitioners need to be able to do it in their office, at least initially before they put their patient who's short of breath on a bronchodilator. They should be able to at least do simple spirometry and make the diagnosis, hopefully air-flow obstruction or not.

I think one of the problems is education and somehow imparting enthusiasm for learning about pulmonary function, which I see lacking in medical students, nursing students, RT students, and even primary care physicians. So we need to work on that. I've been trying to do that in small ways. 